\title{
The impact of patient education and shared decision making on hospital readmissions for COPD
}

This article was published in the following Dove Press journal:

International Journal of COPD

\author{
Ashley W Collinsworth ${ }^{1,2}$ \\ Rachel M Brown' \\ Cameron S James ${ }^{3}$ \\ Richard H Stanford ${ }^{3}$ \\ Daniel Alemayehu' \\ Elisa L Priest ${ }^{\prime}$ \\ 'Center for Clinical Effectiveness, \\ Baylor Scott and White Health, \\ Dallas, TX, USA; ${ }^{2}$ Robbins Institute \\ for Health Policy \& Leadership, \\ Baylor University, Waco, TX, USA; \\ ${ }^{3}$ GlaxoSmithKline, Research Triangle \\ Park, NC, USA
}

\begin{abstract}
Purpose: Education on the self-management of COPD has been shown to improve patients' quality of life and reduce hospital admissions. This study aimed to assess the feasibility of a pilot, pragmatic COPD Chronic Care (CCC) education program led by registered respiratory therapists and determine the CCC's impact on hospital readmissions, patient activation, and health status. Patients and methods: This was a prospective, randomized, pilot study of inpatients with COPD admitted to a US community hospital between August 2014 and February 2016. In total, 308 patients were randomized 1:1 to receive standard care with or without the CCC program. Outcomes included the number of patients completing the program, frequency and time to first all-cause and COPD-related hospital readmissions, and changes in the Patient Activation Measure (PAM) and COPD Assessment Test (CAT).

Results: Overall, $37 \%(n=52)$ of patients in the CCC group and $29 \%(n=48)$ of patients in the control group remained in the study for 6 months and completed all follow-up phone calls. In total, $74 \%(n=105)$ of patients in the CCC group and $69 \%(n=115)$ of patients in the control group had at least one readmission $(P=0.316)$. The time to first all-cause and COPD-related readmission appeared shorter for patients in the CCC group compared with the control group (mean [standard deviation]: 50.2 [54.5] vs 59.9 [63.1] days and 95.1 [80.2] vs 113.7 [82.4] days, respectively; both $P=0.231$ ). Patients experienced significant improvement from baseline in mean PAM (both groups) and CAT (CCC group) scores.

Conclusion: Utilizing respiratory therapists to lead a chronic care education program for COPD in a community hospital was feasible. Although CCC patients showed improvements in perceived symptom severity, they were readmitted sooner than control group patients. However, the program did not impact the frequency of hospital readmissions. A more comprehensive disease management program may be needed to improve outcomes.
\end{abstract}

Keywords: COPD, patient education, shared decision making, hospital readmission, chronic disease management

\section{Introduction}

COPD is the third leading cause of mortality in the US. ${ }^{1}$ It is projected that national medical costs attributable to COPD will increase from \$32.1 billion in 2010 to $\$ 49.0$ billion in 2020. ${ }^{2}$ Although there is no current cure for COPD, appropriate management can result in symptom control, potentially slow the progression of the disease, reduce the frequency and severity of exacerbations, improve lung function, improve quality of life of the patient, and reduce COPD-attributable costs., ${ }^{2,3}$

The study took place at a community hospital located in a low-income suburb of Dallas (TX, USA). The hospital's population faces many challenges, including access to care and lack of a primary care provider, potentially resulting in poor patient education regarding COPD and disease management.
Center for Clinical Effectiveness,

Baylor Scott and White Health, 8080

North Central Expressway, Suite 500,

Dallas, TX 75206, USA

$\mathrm{Tel}+|2| 426536||$

Fax +I 2142653640

Email ashley.collinsworth@bswhealth.org (c) (i) (5) 2018 Collinsworth et al. This work is published and licensed by Dove Medical Press Limited. The full terms of this license are available at https://www.dovepress.com/terms.php cc. ${ }_{\mathrm{BY}} \mathrm{NC}$ and incorporate the Creative Commons Attribution - Non Commercial (unported, v3.0) License (http://creativecommons.org/licenses/by-nch/3.0/). By accessing the work you hereby accept the Terms. Non-commercial uses of the work are permitted without any further permission from Dove Medical Press Limited, provided the work is properly attributed. For permission for commercial use of this work, please see paragraphs 4.2 and 5 of our Terms (https://www.dovepress.com/terms.php). 
To address these challenges, we developed a pilot, pragmatic CCC program. Education on the self-management of COPD has been shown to improve patients' quality of life and reduce hospital admissions, and the CCC program involved training, education, and $\mathrm{SDM}^{4}$ using educational materials specifically tailored for COPD. The goal of the program was to use a personalized self-management plan to improve patient adherence to treatment and disease management (patient activation).

The aims of this study were to assess the feasibility of an RRT-led CCC program and determine the impact of the CCC program on patient outcomes, including hospital readmissions and patient activation.

\section{Patients and methods}

This was a prospective, randomized, pilot study of inpatients with COPD admitted to Baylor Scott \& White Medical Center - Garland. Informed consent was not required for participation in the study. The study was approved by the Baylor Research Institution Institutional Review Board. The Institutional Review Board agreed to a waiver under the Code of Federal Regulation 45 CFR 46.116(d), as the research involved no more than minimal risk to the patient, the rights and welfare of the patient were not adversely affected, and the research could not practicably be carried out without the waiver. The latter was because a key measure of the study was adherence to the CCC program; informing patients on the details of the study could therefore influence this measure.

\section{Inclusion criteria}

This study enrolled all inpatients admitted to the study site from August 20, 2014 to February 7, 2016, who had a diagnosis of COPD at least 24 hours after admission (ICD-9 codes of 491.xx, 492.xx, 496.xx), were $\geq 40$ years of age, and who had access to a telephone.

\section{Exclusion criteria}

Patients were excluded from randomization if they had a primary diagnosis of asthma at the time of admission (ICD-9 codes of 493.xx), a history of pulmonary tuberculosis (ICD-9 codes of 011.xx) or respiratory cancer (ICD-9 codes of 160.xx-163.xx, 231.xx), been referred to hospice care, used a ventilator in hospital for $>10$ days, or a primary language that was not English or Spanish.

\section{Randomization and interventions}

Following an initial run-in period to orient the clinical team to the research process (using standard care only), subsequent patients were randomized 1:1 to the intervention (CCC program) or control group. Randomization was performed using a study identification assignment log where patients were allocated to either treatment group in a sequential order.

Patients randomized to the CCC group who elected to participate in the study underwent baseline evaluation, received COPD education, and participated in SDM self-management planning related to their COPD care priorities with an RRT. The COPD education and SDM self-management planning took place in the hospital and lasted 15-30 minutes. The RRT used SDM principles to help patients choose and focus on strategies that they perceived were most important to maintaining their health and preventing readmission. These strategies included further discussions of COPD symptoms, medication management, appropriate diet and nutrition, stress and coping, and smoking cessation activities. The RRT would then help the participants to create a COPD self-management plan. These patients also received follow-up phone calls lasting 5-10 minutes from the RRT at 3-7 days and 1, 2, and 6 months post-hospital discharge. These calls were guided by a structured checklist and included discussions about COPD exacerbations, health care utilization, the patient's self-management plan, further education, and coaching.

Patients randomized to the control group who elected to participate in the study underwent baseline evaluation and received COPD education from the RRT prior to hospital discharge. These patients also received a follow-up datacollection call at 6 months post-discharge.

\section{Outcomes}

The primary outcome measure to assess the feasibility of an RRT-led CCC program was the number of patients completing the follow-up at 3-7 days, and the number of patients lost to follow-up at 1,2 , and 6 months.

To determine the impact of the CCC program on patient outcomes, we examined the following: the frequency of allcause and COPD-related hospital readmissions at 1, 2, 3, 6, and 9 months; the cumulative incidence of hospital readmission per 100 patient-years; the time to hospital readmission; and the predictors of time to hospital readmission. We also examined the mean change from baseline to 6 months in PAM $^{5}$ and CAT. ${ }^{6}$ The PAM is a measure of patient motivators, attitudes, and behaviors that predicts future hospital admission and treatment adherence. ${ }^{7}$ Scores on the PAM range from 1 , indicating that the patient is disengaged and overwhelmed, to 4, indicating that the patient has adopted and is maintaining healthy behaviors. ${ }^{7}$ The CAT is a measure of health status in COPD on a scale of $0-40$, with lower scores 
$(<10)$ indicating that COPD causes few problems for the patients and higher scores $(>30)$ indicating that COPD prevents the patients from doing most things they want to do. ${ }^{6}$ Readmissions included inpatient, ED, and outpatient (classified as short stay or 24-hour observation and not admitted as inpatients) hospital admissions. Readmissions data were obtained through electronic health records even if the patient did not complete the study calls.

\section{Sample size}

As this was a pilot study, no formal sample size calculations were performed. Based on the frequency of hospital admissions at the study site during 2013, it was estimated that approximately 300 patients would be recruited during a 12-month study. During the course of the study, hospital admissions were less frequent than expected and the recruitment period was extended.

\section{Statistics}

All statistical analyses were performed using $\mathrm{SAS}^{\circledR}$ software version 9.4. For the primary and secondary outcomes, descriptive statistics and distributions were used: comparisons of patient characteristics, completers and noncompleters, and those with or without readmissions were performed using Student's $t$-tests and chi-square tests for continuous and categorical variables, respectively. Riskadjusted negative binomial regression, Kaplan-Meier, and Cox proportional hazards survival analyses were used to determine the impact of the CCC program on (and identify predictors of) the frequency of hospital readmissions and the time to hospital readmissions. Model covariates included age, gender, ethnicity, insurance status, smoking status, baseline CAT and PAM levels, Charlson Comorbidity Index, body mass index, depression (ICD-9 code 311), length of stay, and enrollment quarter. Paired $t$-tests were used to compare CAT and PAM scores; all other exploratory outcomes are presented descriptively, using mean $( \pm \mathrm{SD})$ for continuous variables and frequencies for categorical variables.

\section{Results}

Overall, 750 patients were screened for eligibility, 442 were excluded and 308 were randomized. Including those patients who received standard care during the run-in period to orient the clinical team, $141(46 \%)$ were included in the CCC group and 167 (54\%) in the control group (Figure 1).

Baseline characteristics and demographics are summarized in Table 1. The majority of patients in both groups reported having a regular doctor, help with care, access to transportation, and the ability to obtain medications (77\%-78\% of patients in the CCC group and 69\%-73\% of patients in the control group, all $P>0.05$ ). Other baseline characteristics and demographics were similar between groups, with the exception of the mean number of selfreported hospital visits in the 12 months prior to enrollment, which was significantly higher in the control group than in the CCC group (1.6 vs $1.2, P=0.044)$.

\section{Feasibility}

Overall, 29\% $(n=48)$ of patients in the control group and $37 \%(n=52)$ of patients in the CCC group remained in the study for 6 months and completed all follow-up phone calls. The most common reasons for not completing the follow-up calls were that the patient could not be contacted (34\% [ $n=57]$ vs $37 \%$ [ $n=52]$ in the control vs CCC groups, respectively) or that the patient requested not to be contacted (25\% [n=42] vs $20 \%$ [n=28]). Over $66 \%$ of the patients in the CCC group who completed the first follow-up call completed the study.

Patients who completed the study had a significantly lower Charlson Comorbidity Index score at baseline (mean [SD]: 5.56 [2.46] vs 5.01 [2.04], $P=0.039)$; a significantly shorter hospital length of stay (mean [SD]: 5.2 [3.2] vs 6.1 [4.2] days, $P=0.034)$; and were significantly more likely to report having a regular doctor, help with care, access to transportation, and the ability to obtain medication (89\%-92\% vs $64 \%-68 \%$, all $P<0.001)$ compared with patients who did not complete the study.

As part of the CCC program, the primary areas for coaching focus chosen by the patients were medications $(43 \%$ $[n=60])$, physical activity $(32 \%[n=45])$, smoking cessation $(21 \%[n=29])$, and COPD education $(20 \%$ [n=28]). Patients also chose the development of self-management skills (56\% $[n=79])$ and smoking cessation $(14 \%[n=20])$ as primary treatment options.

\section{Hospital readmissions}

Overall, the intent-to-treat analysis showed that $74 \%(n=105)$ of patients in the CCC group and $69 \%(n=115)$ of patients in the control group had at least one readmission during the course of the study, though this difference was not significant $(P=0.316)$.

Similarly, there were no significant differences in the total number of all-cause or COPD-related readmissions between the CCC and control groups at 6 months (Table 2) or any other time point $(1,2,3$, and 9 months, all $P \geq 0.074)$. 


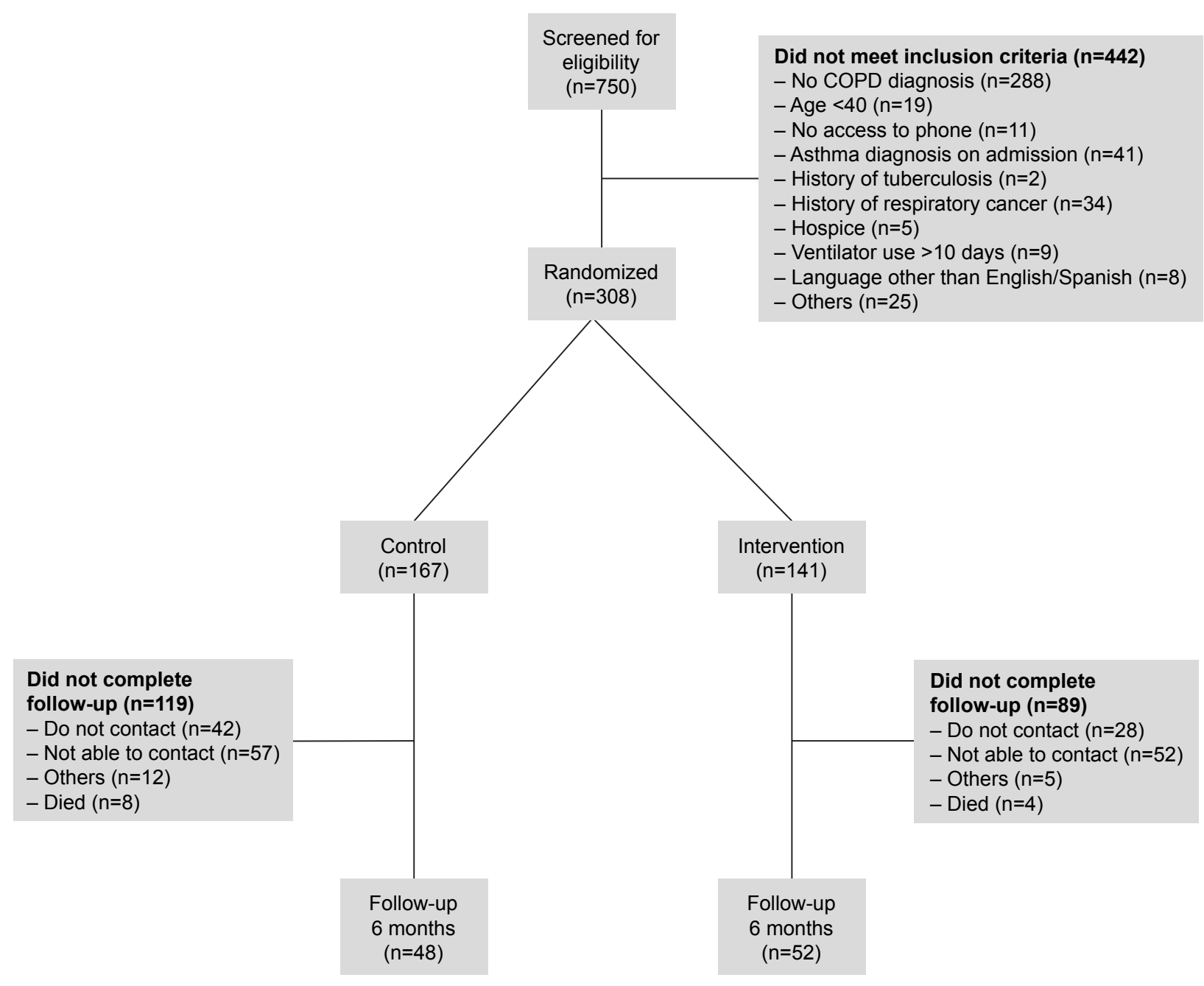

Figure I Patient disposition.

Results from unadjusted and adjusted regression analyses were consistent with the absolute values, and showed no significant impact of the CCC program on all-cause and COPD-related readmissions at any time point (all $P \geq 0.108$ ). When stratified by the type of hospital admission (inpatient, outpatient, ED) the number of all-cause inpatient readmissions was significantly lower in the control group compared with the CCC group at 60 and 90 days $(16.8 \%$ vs $28.4 \%, P=0.031$ and $20.4 \%$ vs $35.5 \%, P=0.008$, respectively). No other significant differences in inpatient, outpatient, or ED readmissions (all-cause or COPD-related) were observed at any other time point.

\section{Incidence of hospital readmission}

The cumulative incidence of COPD-related readmissions appeared greater in the CCC group compared with the control group (75.7 vs $56.3 / 100$ patient-years, $P=0.024$, respectively), though all-cause readmissions were similar (424.4 vs 423.9/100 patient-years, $P=0.984$ ).

\section{Time to hospital readmission}

Kaplan-Meier analyses of the time to first all-cause and COPD-related hospital readmission are presented in Figures 2 and 3. Overall, the time to first all-cause and COPD-related readmission was shorter for patients in the CCC group compared with the control group (mean [SD]: 50.2 [54.5] vs 59.9 [63.05] days and 95.1 [80.2] vs 113.7 [82.4] days, respectively), though these differences were not significant (both $P \geq 0.231$ ).

Cox proportional hazards modeling showed that (i) a higher score on the Charlson Comorbidity Index, indicating a greater number of comorbidities, was associated with a shorter time to first all-cause readmission $(P=0.031)$, and (ii) a higher CAT score at baseline was associated with a shorter time to first COPD-related readmission $(P=0.014)$. 
Table I Baseline demographics and characteristics

\begin{tabular}{|c|c|c|c|}
\hline Characteristics & $\begin{array}{l}\text { Control } \\
\text { group } \\
(n=167)\end{array}$ & $\begin{array}{l}\text { CCC } \\
\text { group } \\
(n=141)\end{array}$ & $P$-value \\
\hline Age, mean (SD) (years) & $70.9(12.5)$ & 70.0 & 0.533 \\
\hline Female, n (\%) & $95(56.9)$ & $85(60.3)$ & 0.547 \\
\hline \multicolumn{4}{|l|}{ Ethnicity, n (\%) } \\
\hline Hispanic & $9(5.4)$ & $6(4.3)$ & 0.645 \\
\hline Not hispanic & $158(94.6)$ & $135(95.7)$ & \\
\hline \multicolumn{4}{|l|}{ Smoking status, n (\%) } \\
\hline Current smoker & $50(29.9)$ & 47 (33.3) & 0.079 \\
\hline Former smoker & 75 (44.9) & $57(40.4)$ & \\
\hline Never smoked & $26(15.6)$ & $32(22.7)$ & \\
\hline \multicolumn{4}{|l|}{ PAM score, $n(\%)$} \\
\hline I & $42(31.8)$ & $38(31.7)$ & 0.564 \\
\hline 2 & $57(43.2)$ & $46(38.3)$ & \\
\hline 3 & $32(24.2)$ & $36(30.0)$ & \\
\hline 4 & $\mathrm{I}(0.8)$ & $0(0.0)$ & \\
\hline \multicolumn{4}{|l|}{ GOLD category, ${ }^{*} \mathrm{n}(\%)$} \\
\hline I $\left(\mathrm{FEV}_{1} \geq 80 \%\right.$ predicted $)$ & $2(7.4)$ & $3(12.0)$ & $0.44 I$ \\
\hline $2(50 \% \leq \mathrm{FEV},<80 \%$ predicted $)$ & $23(85.2)$ & $17(68.0)$ & \\
\hline $3(30 \% \leq \mathrm{FEV},<50 \%$ predicted $)$ & $2(7.4)$ & $4(16.0)$ & \\
\hline $4\left(\mathrm{FEV}_{1}<30 \%\right.$ predicted $)$ & $0(0.0)$ & I (4.0) & \\
\hline \multicolumn{4}{|l|}{ CAT category, $\mathrm{n}(\%)$} \\
\hline Low (score of 0-9) & $10(7.6)$ & $3(2.5)$ & 0.068 \\
\hline Medium (score of 10-19) & $35(26.7)$ & $37(30.8)$ & \\
\hline High (score of 20-29) & $70(53.4)$ & $55(45.8)$ & \\
\hline Very high (score of 30-40) & $16(12.2)$ & $25(20.8)$ & \\
\hline CAT score, mean & 22.3 & 22.8 & 0.6981 \\
\hline $\begin{array}{l}\text { Charlson Comorbidity Index, } \\
\text { mean (SD) }\end{array}$ & $5.45(2.27)$ & $5.29(2.44)$ & 0.559 \\
\hline BMI, mean $(\mathrm{SD})\left(\mathrm{kg} / \mathrm{m}^{2}\right)$ & $30.3(13.8)$ & $29.7(9.5)$ & 0.680 \\
\hline \multicolumn{4}{|l|}{ Previous hospital utilization ${ }^{* *}$} \\
\hline Hospital visits, mean (SD) & $1.6(2.0)$ & $1.2(1.3)$ & 0.044 \\
\hline ED visits, mean (SD) & $1.9(2.3)$ & $1.4(1.9)$ & 0.077 \\
\hline Index admission LOS, mean (SD) (days) & $5.9(4.1)$ & $5.6(3.6)$ & 0.536 \\
\hline \multicolumn{4}{|c|}{ Patients completing follow-up calls post-discharge, $n(\%)$} \\
\hline $3-7$ days & NA & $78(55.3)$ & \\
\hline 30 days & NA & $62(44.0)$ & \\
\hline 60 days & NA & $61(43.2)$ & \\
\hline 180 days & $48(28.7)$ & $52(36.9)$ & \\
\hline
\end{tabular}

Notes: *Most recent GOLD categorization during the 12 months prior to, or 2 weeks following, hospital admission. **Self-reported in the 12 months prior to study enrollment.

Abbreviations: BMI, body mass index; CAT, COPD Assessment Test; CCC, COPD Chronic Care; ED, emergency department; GOLD, Global initiative for chronic Obstructive Lung Disease; LOS, length of stay; NA, not applicable; PAM, Patient Activation Measure; SD, standard deviation.

\section{PAM and CAT}

In both the CCC and control groups, patients who completed the study showed a significant improvement (increase) from baseline in mean PAM score at the end of the study (difference [SD]: 0.52 [0.94] and 0.69 [0.96] points, respectively, both $P<0.001$ ) which could be due to the fact that both groups were more aware of their disease during the study. However, only patients in the $\mathrm{CCC}$ group experienced a significant improvement from baseline in mean CAT score (difference [SD]: CCC -5.27 [10.26], $P<0.001$; control -0.38 [7.78], $P=0.740)$.

\section{Discussion}

The results of this prospective, randomized, pilot study at a suburban, community hospital show that implementing the CCC program utilizing respiratory therapy team members to contact patients with COPD after discharge was feasible, with over a third of patients retained after 6 months. The observed completion rate for this study is comparable to completion rates for other standard COPD management interventions, such as pulmonary rehabilitation, for which attrition rates as high as $60 \%$ have been reported. ${ }^{8,9}$ However, this additional contact did not have a significant impact on the frequency of all-cause or COPD-related hospital admissions, either in crude or adjusted models. Patients in the CCC group had significantly more inpatient readmissions at 60 and 90 days, though this difference was not seen for any other time point or for outpatient or ED readmissions. Despite a lack of any significant impact of the CCC program on hospital admissions, a significant decrease in CAT score 6 months following the intervention indicated that patients in the CCC group perceived improvements in COPD symptoms and a reduced impact of COPD on their well-being and activities of daily life.

Although the CCC program had no significant impact on the overall frequency of hospital readmissions, the time to first all-cause hospital readmission appeared to be shorter in the CCC group compared with the control group. This was an unexpected result, especially considering the significant improvements in patient health status reflected by CAT scores. It is possible that patients in the $\mathrm{CCC}$ group were more aware of early symptoms as a result of the education they received, and were therefore more proactive in seeking care at symptom onset rather than waiting for an exacerbation. It is also possible that there were underlying differences between the study groups that were not identified, and which contributed to this difference.

COPD negatively impacts patients' quality of life and often results in costly hospital readmissions. However, few interventions have shown to be effective in preventing hospital readmissions due to COPD exacerbations. In a 2013 systematic literature review of randomized controlled trials, Prieto-Centurion et al concluded that no specific non-pharmacological interventions or bundle of interventions could be identified that effectively reduced the rate of hospital readmissions in patients with COPD. ${ }^{10}$ 
Table 2 All-cause and COPD-related readmissions at 6 months

\begin{tabular}{|c|c|c|c|c|c|c|}
\hline \multirow{2}{*}{$\begin{array}{l}\text { Number of } \\
\text { readmissions } \\
\text { at } 6 \text { months }\end{array}$} & \multicolumn{3}{|c|}{ All-cause readmissions } & \multicolumn{3}{|c|}{ COPD-related readmissions } \\
\hline & $\begin{array}{l}\text { Control } \\
(n=167)\end{array}$ & $\begin{array}{l}\text { CCC group } \\
(n=\mid 4 I)\end{array}$ & $P$-value & $\begin{array}{l}\text { Control } \\
(n=167)\end{array}$ & $\begin{array}{l}\text { CCC group } \\
(n=\mid 4 I)\end{array}$ & $P$-value \\
\hline \multicolumn{3}{|l|}{ Inpatient, n (\%) } & 0.242 & & & 0.099 \\
\hline 0 & $106(63.5)$ & $72(51.1)$ & & $154(92.2)$ & $119(84.4)$ & \\
\hline 1 & $35(21.0)$ & $4 I(29.1)$ & & II (6.6) & $20(14.2)$ & \\
\hline 2 & $17(10.2)$ & $18(12.8)$ & & $2(1.2)$ & $\mathrm{I}(0.7)$ & \\
\hline$\geq 3$ & $9(5.4)$ & $10(7.1)$ & & $0(0.0)$ & $\mathrm{I}(0.7)$ & \\
\hline \multicolumn{3}{|l|}{ ED, n (\%) } & 0.477 & & & 0.424 \\
\hline 0 & $117(70.1)$ & $103(73.1)$ & & $160(95.8)$ & $132(93.6)$ & \\
\hline 1 & $25(15.0)$ & $19(13.5)$ & & $6(3.6)$ & $8(5.7)$ & \\
\hline 2 & $13(7.8)$ & $13(9.2)$ & & $0(0.0)$ & I (0.7I) & \\
\hline$\geq 3$ & $12(7.2)$ & $6(4.3)$ & & I (0.6) & $0(0.0)$ & \\
\hline \multicolumn{3}{|c|}{ Outpatient/short stay, n (\%) } & 0.195 & & & 0.904 \\
\hline 0 & $100(59.9)$ & $83(58.9)$ & & $153(91.6)$ & $128(90.8)$ & \\
\hline 1 & $40(24.0)$ & $27(19.2)$ & & $9(5.4)$ & $9(6.4)$ & \\
\hline 2 & $9(5.4)$ & $14(9.9)$ & & $3(1.8)$ & $3(2.1)$ & \\
\hline$\geq 3$ & $18(10.8)$ & I7 (II.3) & & $2(1.2)$ & I (0.7) & \\
\hline \multicolumn{3}{|l|}{ Total, n (\%) } & 0.401 & & & 0.152 \\
\hline 0 & $62(37.1)$ & $39(27.7)$ & & |4| (84.4) & $109(77.3)$ & \\
\hline 1 & 32 (19.2) & $28(19.9)$ & & $17(10.2)$ & $19(13.5)$ & \\
\hline 2 & $23(13.8)$ & $23(16.3)$ & & $4(2.4)$ & $8(5.7)$ & \\
\hline$\geq 3$ & $50(30.0)$ & $51(36.2)$ & & $5(3.0)$ & $5(3.5)$ & \\
\hline
\end{tabular}

Abbreviations: CCC, COPD Chronic Care; ED, emergency department.

The five studies included in this literature review utilized various combinations of interventions including education, self-management training, exercise programs, case managers, and group sessions. ${ }^{11-15}$ Of these five studies, which were all of a similar size to the one reported here (155-464 participants), ${ }^{10}$ only two reported a significant reduction in all-cause hospital readmissions as a result of an intervention. ${ }^{11,13}$ Bourbeau et al found that patients

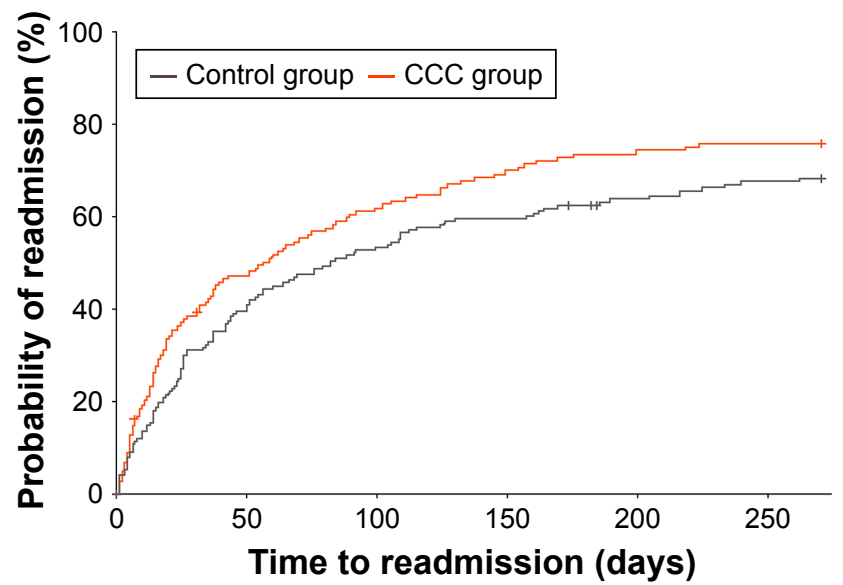

Figure 2 Time to all-cause readmission (inpatient, ED, or outpatient). Notes: Outpatients: classified as patients with short stay or 24-hour observation and not admitted as inpatients. Cross mark indicates patient death. Abbreviations: CCC, COPD Chronic Care; ED, emergency department. who participated in a 2-month comprehensive patient selfmanagement and education program with monthly telephone follow-up by case managers had fewer readmissions at 12 months than patients in the control group. ${ }^{11}$ Similarly, Casas et al found that an integrated care program consisting of an individually tailored care plan upon discharge and access to a specialized nurse case manager through a web-based call center was effective in reducing hospital readmissions over

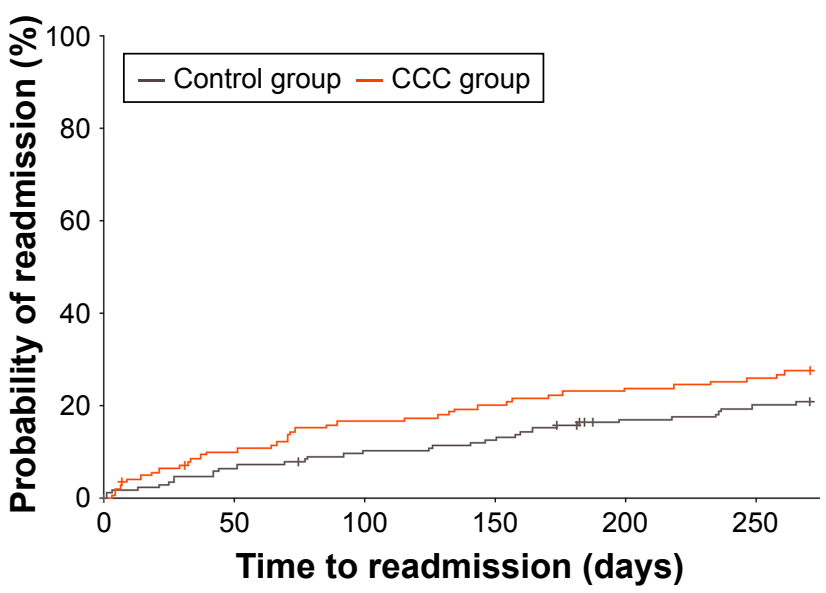

Figure 3 Time to first COPD-related readmission (inpatient, ED, or outpatient). Notes: Outpatients: classified as patients with short stay or 24-hour observation and not admitted as inpatients. Cross mark indicates patient death. Abbreviations: CCC, COPD Chronic Care; ED, emergency department. 
a 12-month period. However, the authors of both of these studies recognized that it was impossible to determine the impact of the individual components of these multifaceted interventions on the observed outcomes. ${ }^{11,13}$

In a recent study, Benzo et al sought to address the knowledge gap regarding effective approaches to reducing COPD readmissions, particularly in the short term, by examining the effect of comprehensive health coaching on the rate of COPD readmissions at 1,3,6,9, and 12 months. ${ }^{16}$ At hospital discharge, patients $>40$ years of age hospitalized for a COPD exacerbation $(\mathrm{N}=215)$ were randomized to receive either (i) motivational interview-based health coaching alongside a written action plan for exacerbations and brief exercise advice or (ii) usual care. ${ }^{16}$ Although the intervention was similar to the intervention in our study, Benzo et al found the health coaching intervention to be effective in the short run as patients in the intervention group were significantly less likely to be readmitted at 1, 3, and 6 months compared with patients in the control group. ${ }^{16}$ However, there were no statistically significant differences in readmission between the groups at 12 months post-discharge. ${ }^{16}$

The positive outcomes observed by Benzo et al in the short term may be attributable to having a more robust and standardized intervention, and to the fact that patients in the intervention group had higher attendance for conventional pulmonary rehabilitation in the first 3 months following discharge than patients in the control group (50\% vs $33 \%, P=0.017)$, ${ }^{16}$ which has been shown to be a highly effective intervention for COPD. ${ }^{3}$ Patients in our study were given information about pulmonary rehabilitation, but pulmonary rehabilitation was not available at the study site. The patients in our study also had a greater number of comorbidities as indicated by a higher Charlson Comorbidity Index score compared with patients in the Benzo et al study (5.3-5.5 vs 3.0-3.7, respectively) and may have differed in socioeconomic status.

The findings from this study and the current literature indicate that multifaceted and comprehensive interventions are needed to counter the complex and progressive nature of COPD; however, it is unclear what intervention components or combinations thereof may drive consistent improvements in patient outcomes, particularly reductions in hospital readmissions. The fact that the majority of patients who failed to complete the study could not be or requested not to be contacted by phone for the first study follow-up call indicates that other forms of intervention and communication may be preferred. Management of COPD may be more challenging in populations that are sicker and socioeconomically disadvantaged. Although a surprisingly high percentage of patients in this study indicated that they had a regular doctor, help with care, and access to medications and transportation, many of them had multiple comorbidities. Our results suggest that a more comprehensive chronic disease intervention than the CCC program may be required to reduce hospital readmissions at facilities treating complex and traditionally underserved patients with COPD.

\section{Limitations}

Limitations to be considered when interpreting the results of this study include the heterogeneity of the patient population, although this was due to the study design and setting, and the limited collection of data on patient comorbidities beyond the evaluation of the Charlson Comorbidity Index. As the Charlson Comorbidity Index was shown to be a significant predictor of the time to first hospital readmission, characterization of the comorbidities present in a real-world COPD population should be important in future studies of interventions aimed at improving the management of COPD and patients' quality of life. Interventions were also tailored to meet the COPD-related care priorities of individual patients, which may have resulted in variations in behavior that were not assessed or quantified (eg, focus, duration of RRT discussion, intensity of discussion sessions). Finally, the study was limited to a single center, meaning that changes to that center which were not assessed (eg, staff turnover) could also have impacted on the delivery of the CCC program.

\section{Conclusion}

The results of this study showed that implementing the CCC program was feasible and had a positive impact on patients' perceived health status. The program itself, however, did not impact the overall frequency of hospital readmissions, but may have improved the self-awareness of symptoms leading to a shortened time to first all-cause readmissions. A more comprehensive disease management program may be needed to drive improvements in patient outcomes.

\section{Abbreviations}

CAT, COPD Assessment Test; CCC, COPD Chronic Care; ED, emergency department; ICD-9, International Classification of Diseases, Ninth Revision; PAM, Patient Activation Measure; RRT, registered respiratory therapist; SD, standard deviation; SDM, shared decision making.

\section{Acknowledgments}

This study was conducted by the respiratory therapy team at Baylor Scott \& White Medical Center - Garland and funded by GSK (GSK study ID: HO-13-13904). Additional 
study support including chart abstraction, follow-up phone calls, and data management was provided by Louann Cole, Lauren Hall, Amos Hayes, Maria Kouznetsova, Brandy McDonald, and Taoran Qiu. Editorial support (in the form of writing assistance, including development of the initial draft, assembling tables and figures, collating author comments, and grammatical editing, and referencing) was provided by Rachel Edwards of Fishawack Indicia Ltd. (Knutsford, Cheshire, UK) and was funded by GSK. No funding was provided to Baylor Scott \& White Medical Center - Garland for manuscript development. This manuscript has not been previously published and is not under consideration in the same or substantially similar form in any other peer-reviewed media. Some data from this study were presented as a poster at the AcademyHealth 2017 Annual Research Meeting in New Orleans, LA, USA.

\section{Author contributions}

ELP and AWC were involved in the conception and design of the study, the acquisition of data, and the data analysis and interpretation. RHS was involved in the conception and design of the study, and the data analysis and interpretation. RMB and DA were involved in the acquisition of data and the data analysis and interpretation. CSJ was involved in the data analysis and interpretation. All authors contributed to the writing and reviewing of the manuscript, and have given final approval of the version to be published.

\section{Disclosure}

RHS is an employee of GSK and holds stocks/shares in GSK. CSJ is a current employee of Sanofi and was an employee of GSK during the study and still holds stocks/shares in GSK. AWC, RMB, DA, and ELP have received research funding from GSK. The authors report no other conflicts of interest in this work.

\section{References}

1. American Lung Association. Trends in COPD (chronic bronchitis and emphysema): morbidity and mortality. 2013. Available from: http://www. lung.org/assets/documents/research/copd-trend-report.pdf. Accessed December 10, 2017.
2. Ford ES, Murphy LB, Khavjou O, Giles WH, Holt JB, Croft JB. Total and state-specific medical and absenteeism costs of COPD among adults aged $\geq 18$ years in the United States for 2010 and projections through 2020. Chest. 2015;147(1):31-45.

3. Global Initiative for Chronic Obstructive Lung Disease (GOLD). Global strategy for the diagnosis, management and prevention of chronic obstructive pulmonary disease 2017 report. Available from: http://goldcopd.org/gold-2017-global-strategy-diagnosis-managementprevention-copd/. Accessed December 10, 2017.

4. Legare F. Shared decision making: moving from theorization to applied research and hopefully to clinical practice. Patient Educ Couns. 2013;91(2):129-130.

5. Hibbard JH, Stockard J, Mahoney ER, Tusler M. Development of the Patient Activation Measure (PAM): conceptualizing and measuring activation in patients and consumers. Health Serv Res. 2004;39(4 Pt 1): 1005-1026.

6. Jones PW, Harding G, Berry P, Wiklund I, Chen WH, Kline Leidy N. Development and first validation of the COPD Assessment Test. Eur Respir J. 2009;34(3):648-654.

7. Insignia Health ${ }^{\circledR}$. Patient Activation Measure ${ }^{\circledR}(P A M \circledR)$. Available from: http://www.insigniahealth.com/products/pam-survey. Accessed December 10, 2017.

8. Brown AT, Hitchcock J, Schumann C, Wells JM, Dransfield MT, Bhatt SP. Determinants of successful completion of pulmonary rehabilitation in COPD. Int J Chron Obstruct Pulmon Dis. 2016;11:391-397.

9. Barr PJ, Forcino RC, Thompson R, et al. Evaluating CollaboRATE in a clinical setting: analysis of mode effects on scores, response rates and costs of data collection. BMJ Open. 2017;7(3):e014681.

10. Prieto-Centurion V, Markos MA, Ramey NI, et al. Interventions to reduce rehospitalizations after chronic obstructive pulmonary disease exacerbations. A systematic review. Ann Am Thorac Soc. 2014;11(3): 417-424.

11. Bourbeau J, Julien M, Maltais F, et al; Chronic Obstructive Pulmonary Disease axis of the Respiratory Network Fonds de la Recherche en Santé du Québec. Reduction of hospital utilization in patients with chronic obstructive pulmonary disease: a disease-specific self-management intervention. Arch Intern Med. 2003;163(5):585-591.

12. Kwok T, Lum CM, Chan HS, Ma HM, Lee D, Woo J. A randomized, controlled trial of an intensive community nurse-supported discharge program in preventing hospital readmissions of older patients with chronic lung disease. J Am Geriatr Soc. 2004;52(8):1240-1246.

13. Casas A, Troosters T, Garcia-Aymerich J, et al; members of the CHRONIC Project. Integrated care prevents hospitalisations for exacerbations in COPD patients. Eur Respir J. 2006;28(1):123-130.

14. Bucknall CE, Miller G, Lloyd SM, et al. Glasgow supported selfmanagement trial (GSuST) for patients with moderate to severe COPD: randomised controlled trial. BMJ. 2012;344:e1060.

15. Fan VS, Gaziano JM, Lew R, et al. A comprehensive care management program to prevent chronic obstructive pulmonary disease hospitalizations: a randomized, controlled trial. Ann Intern Med. 2012;156(10): 673-683.

16. Benzo R, Vickers K, Novotny PJ, et al. Health coaching and chronic obstructive pulmonary disease rehospitalization. A randomized study. Am J Respir Crit Care Med. 2016;194(6):672-680.
International Journal of COPD

\section{Publish your work in this journal}

The International Journal of COPD is an international, peer-reviewed journal of therapeutics and pharmacology focusing on concise rapid reporting of clinical studies and reviews in COPD. Special focus is given to the pathophysiological processes underlying the disease, intervention programs, patient focused education, and self management protocols.

\section{Dovepress}

This journal is indexed on PubMed Central, MedLine and CAS. The manuscript management system is completely online and includes a very quick and fair peer-review system, which is all easy to use. Visit $\mathrm{http}: / /$ www.dovepress.com/testimonials.php to read real quotes from published authors. 